\title{
Distinct Pathways Involved in Sound Recognition and Localization: A Human fMRI Study
}

\author{
Philippe P. Maeder,*,1 Reto A. Meuli,* Michela Adriani,† Anne Bellmann,†† Eleonora Fornari,§ \\ J ean-Philippe Thiran,§ Antoine Pittet, ๆ and Stéphanie Clarke†ł \\ *Service de Radiodiagnostic et Radiologie Interventionnelle and †Division de Neuropsychologie, CHUV, Lausanne; \\ ¥Institut de Physiologie, Université de Lausanne; §L aboratoire de Traitement des Signaux, \\ Ecole Polytechnique Fédérale, Lausanne; and IE cole d'Ingénieurs, Genève, Switzerland
}

Received November 13, 2000

Evidence from psychophysical studies in normal and brain-damaged subjects suggests that auditory information relevant to recognition and localization are processed by distinct neuronal populations. We report here on anatomical segregation of these populations. Brain activation associated with performance in sound identification and localization was investigated in 18 normal subjects using fMRI. Three conditions were used: (i) comparison of spatial stimuli simulated with interaural time differences; (ii) identification of environmental sounds; and (iii) rest. Conditions (i) and (ii) required acknowledgment of predefined targets by pressing a button. After coregistering, images were normalized and smoothed. Activation patterns were analyzed using SPM99 for individual subjects and for the whole group. Sound recognition and localization activated, as compared to rest, inferior colliculus, medial geniculate body, Heschl gyrus, and parts of the temporal, parietal, and frontal convexity bilaterally. The activation pattern on the fronto-temporo-parietal convexity differed in the two conditions. Middle temporal gyrus and precuneus bilaterally and the posterior part of left inferior frontal gyrus were more activated by recognition than by localization. Lower part of inferior parietal lobule and posterior parts of middle and inferior frontal gyri were more activated, bilaterally, by localization than by recognition. Regions selectively activated by sound recognition, but not those selectively activated by localization, were significantly larger in women. Passive listening paradigm revealed segregated pathways on superior temporal gyrus and inferior parietal lobule. Thus, anatomically distinct networks are involved in sound recognition and sound localization. 2001 Academic Press

\section{INTRODUCTION}

Hearing a sound in natural surroundings conveys at least two types of information. It allows us to identify

\footnotetext{
${ }^{1}$ To whom correspondence and reprint requests should be addressed. Fax: 4121314 4554. E-mail: Philippe.Maeder@chuv.hospvd.ch.
}

the sound source and determine its position in space. While evidence from psychophysical studies suggests that sound recognition and sound localization are processed independently (Clarke et al., 1998), evidence from activation and neuropsychological studies demonstrates the involvement of distributed cortical networks including the temporal, parietal, and prefrontal cortex of both hemispheres.

Recent activation studies demonstrated that a sound categorization task activated a distributed left-hemisphere network consisting of dorsolateral prefrontal, middle temporal, inferior parietal, and anterior cingulate regions (Engelien et al., 1995). Neuropsychological studies showed that focal hemispheric lesions, involving the right (Spreen et al., 1965; Spinnler and Vignolo, 1966; Faglioni et al., 1969; Vignolo, 1982; Fujii et al., 1990; Schnider et al., 1994; Clarke et al., 1996), left (Spinnler and Vignolo, 1966; Faglioni et al., 1969; Vignolo, 1982; Schnider et al., 1994; Clarke et al., 1996; Clarke et al., 2000a), or both hemispheres (Albert et al., 1972; Rosati et al., 1982; Vignolo, 1982; Mendez and Geehan, 1988; Buchtel and Stewart, 1989; Engelien et al., 1995; Clarke et al., 1996; Nové-J osserand et al., 1998) were associated with sound recognition deficits.

Similarly, sound localization was shown to activate largely distributed cortical networks with an important contribution of the temporal, parietal and prefrontal cortices (Griffiths et al., 1998, 2000; Bushara et al., 1999). Some authors suggested right hemispheric dominance (Griffiths et al., 1998; Weeks et al., 1999), whereas others found no evidence for lateralization in auditory spatial processing (Bushara et al., 1999; Woldorff et al., 1999). Neuropsychological studies showed that sound localization deficits were associated with focal lesions of the right or left hemisphere (Sanchez-Longo and Forster, 1958; Klingon and Bontecou, 1966; Efron et al., 1983; Poirier et al., 1994; Zatorre et al., 1995; Haeske-Dewick et al., 1996) and right hemisphere specialization for auditory spatial functions has been proposed (Altman et al., 1979; Ruff 
et al., 1981; Bisiach et al., 1984; Pinek and Brouchon, 1992). While some authors attributed impaired sound localization exclusively to lesions in the temporal lobe (Sanchez-Longo and Forster, 1958; Efron et al., 1983), others questioned its importance in sound localization (J erger et al., 1972) or reported auditory spatial deficits following parietal lobe lesions (Bisiach et al., 1984; Pinek and Brouchon, 1992; Griffiths et al., 1997).

The question arises whether sound recognition and sound localization involve at least partially segregated networks. We report here on activation patterns to sound recognition and to sound localization that strongly suggest such a possibility. Preliminary results were published in abstracts (Maeder et al., 2000; Clarke et al., 2000b).

\section{MATERIALS AND METHODS}

\section{Subjects}

Eighteen normal subjects, aged 23- 47 years, participated in this study; 8 were female (mean age 31.1 years, SD $=9.1$ years) and 10 male (mean age 27.7 years; SD $=4.1$ years). All subjects were right-handed, as established by means of the Oldfield questionnaire (Oldfield, 1971), without previous history of neurological or psychiatric illness and with normal audition. Informed consent was obtained from all subjects before testing.

\section{Experimental Protocol}

Brain activation associated with sound recognition or sound localization was investigated with a triple epoch fMRI study (recognition-localization-rest). Two paradigms were used, one active, requiring a motor response, and one passive, requiring no response. In a first study with 18 subjects both tasks were active and required the subject's response (for a similar approach see Grady et al., 1997; J äncke et al., 1999). The stimuli were 5-s-long stimuli and consisted of sound background and sound targets (Fig. 1).

In the recognition task, the background consisted of an everyday auditory scene. Five different backgrounds were used (market place, street, beach, shop, railway station) and presented each six times. Targets were meaningful, environmental sounds lasting $2 \mathrm{~s}$ and starting $1.5 \mathrm{~s}$ after the background onset (Fig. 1). Subjects were required to press a pneumatic device, with their right hand in response to animal cries. Each presentation contained an unusual sound, but only animal cries had to be acknowledged. The detection of a particular target was not possible on the sole basis of acoustical cues. The complexity of targets did not allow a subject to memorize the backgrounds sufficiently to be able to detect putative targets as frequency and/or intensity deviants. The unusual sounds could also not

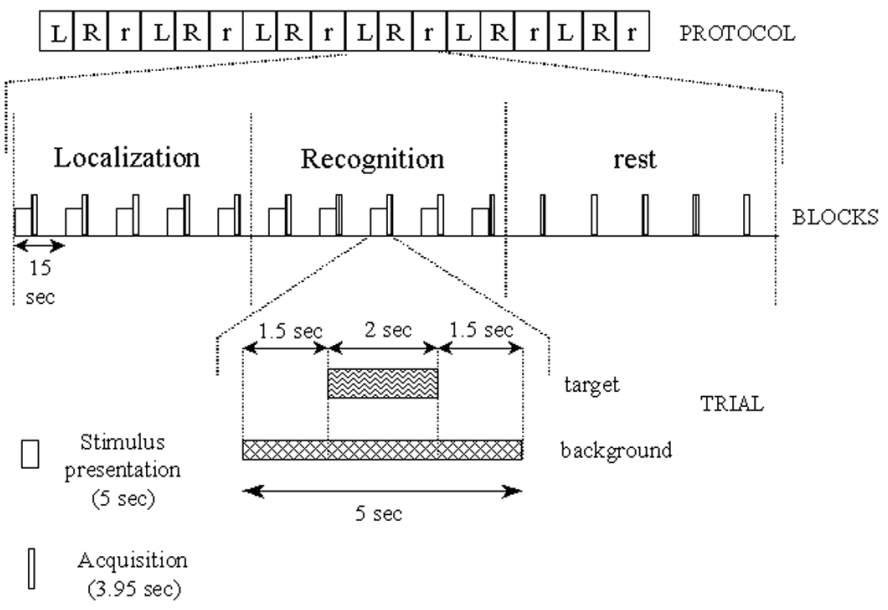

FIG. 1. Schematic representation of the experimental paradigm, the blocks, and the structure of the stimuli. R, recognition task; $L$, localization task; $r$, rest.

be detected as pop-out. The unusual sounds (including targets) were louder by only $9 \mathrm{~dB}$ than the mean background intensity to avoid a too easy target-background discrimination, and the overall impression was that of merging with the background intensity while still remaining audible. Auditory background and targets presented frequency and intensity modulations and contained burst-like (intermittent) sounds (e.g., hammer, church bells, ducks).

In the localization task, the background consisted of 25 white noise bursts, each lasting $50 \mathrm{~ms}$, with interaural time differences varying between 0 and $681 \mu \mathrm{s}$ and hence simulating different azimuthal positions. The targets consisted of two 500-ms-long, filtered white noise tracts (low-pass $1000 \mathrm{~Hz}$ ), the first presented $1.5 \mathrm{~s}$ and the second $3 \mathrm{~s}$ after the onset of the background (Fig. 1). The task consisted in discriminating whether the two targets were presented at the same or at two different locations within the same hemifield; when two different locations were used, the difference between the interaural time differences was $340.5 \mu \mathrm{s}$. As in the recognition task, the target volume was $9 \mathrm{~dB}$ louder than the background. Subjects were required to press a pneumatic device with their right hand when the targets were at different locations. The subjects were asked to discriminate two locations within the same hemispace; we refer to this as "localization."

The mean intensities in the recognition and localization tasks were similar.

In each condition, 30 stimuli were presented, of which 16 required a manual response. During acquisition, the tasks were presented in blocks of 5 trials: 5 acquisitions for the localization task, 5 for the recognition task and 5 for rest (Fig. 1). The presentation order of the three conditions was not counterbalanced between participants, since we aimed at single subject analysis. 

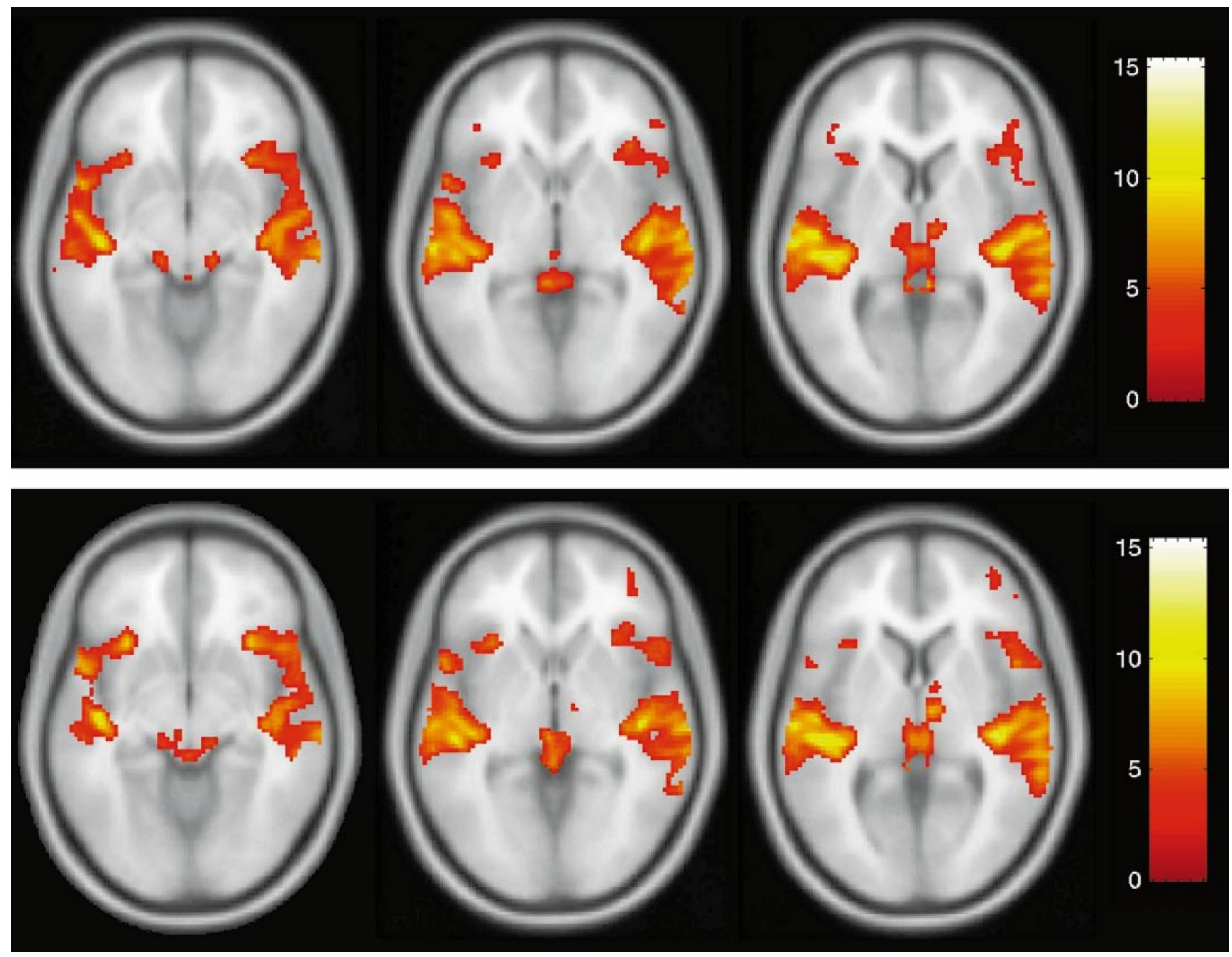

FIG. 2. Group results for recognition (top row) and localization (bottom row) versus rest displayed on two sets of axial slices ( $z=-8,-2$, +4 ) showing strong activation in auditory subcortical relays as well as primary auditory and surrounding cortex. The left side of the figure corresponds to the left hemisphere.

In a second study with nine subjects the same set of stimuli was used, but an active response was not required. The subjects were instructed "to listen to the auditory stimuli." The nine subjects participating in this paradigm had not performed the active tasks before.

The subjects lay in the scanner with eyes closed and room light extinguished. They were asked not to move their eyes or their body during the experiment and were instructed to relax during periods without stimulation. Eye movements were not recorded. Although, more generally, the activity of the subjects during the rest condition could not be controlled, what they did during rest cannot have appreciably influenced the main results of our study; the subtraction recognition versus localization analysis did not involve the rest condition.

\section{Sound Generation and Transmission}

Digitally synthesized sounds (Macintosh, Sound designer II, Protools Powermix) and real recorded sounds were loaded in an audio sampler-sequencer (MCP2000, Akai, J apan) for synchronization with the fMRI acquisition. The audio signal was digitally filtered with a 31-band (1/3 octave frequency each) stereo equalizer (Ultracurve Behringer, Willich-MŸnchheide, FRG), for correction of the nonlinearity of the transducers driving the pneumatic earphones, and amplified. The spectral content of the stimuli was confined to the resulting linear part of the bandwidth $(500-4000 \mathrm{~Hz})$.

The sound transmission system was made of pneumatic headphones chosen to fit in the head coil of the scanner with a high attenuation of the external noise, connected to piezoelectric transducers inserted in alu- 


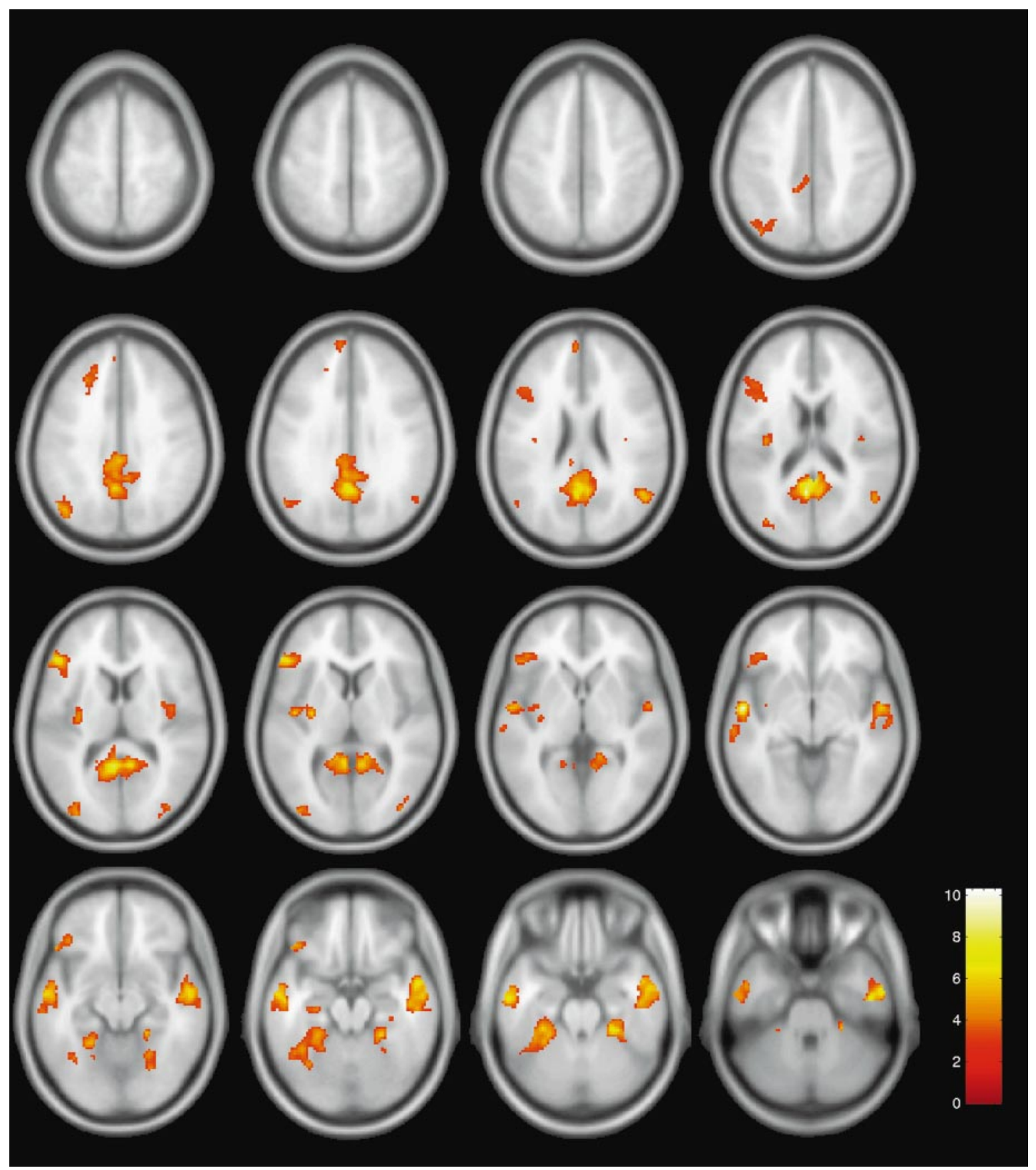

FIG. 3. Recognition versus localization on axial slices ( $z=60$ to -30 ). The left side of the figure corresponds to the left hemisphere.

minum boxes (Newmatic Sound System, Petaluma, CA) located at the subject's feet. Coaxial cables were used from the power amplifier to the transducers, crossing the filter plate of the Faraday cage of the examination room.

\section{Functional Magnetic Resonance Imaging}

BOLD fMRI acquisitions were performed with a head coil on a 1.5 Tesla Siemens Magnetom Vision system equipped for echoplanar imaging. The subject's head was cushioned in the coil with a vacuum bean bag to prevent motion. Sixteen slices, each $5 \mathrm{~mm}$ thick, with $1 \mathrm{~mm}$ gap covering the whole hemispheres in the bicommissural plane were acquired. Functional MRI images were acquired with an EPI gradient echo T2*weighted sequence (FA 90, TE 66, pixel size $1.8 \times 1.8$ $\mathrm{mm}$, acquisition time $3.95 \mathrm{~s})$. The $5 \mathrm{~s}$ of stimulus pre sentation immediately preceded the acquisition. A long TR of $15 \mathrm{~s}$ and careful adjustment of the timing of the stimuli presentation allowed acquisition of the $\mathrm{fMRI}$ 
data only during the BOLD effect elicited by the stimuli. Thanks to this "sparse" sampling technique (Belin et al., 1999; Hall et al., 1999; Meuli et al., 2000) interference with the BOLD effect elicited by the gradient noise could be avoided. The 5-s stimuli were presented in alternation with rest for a total of 90 epochs over 22 $\min , 30 \mathrm{~s}$.

A sagittal conventional T1-weighted 3D gradientecho sequence (MPRAGE), 128 slices, $1.25 \mathrm{~mm}$ thick was acquired as the structural basis for Talairach transformation (Talairach and Tournoux, 1988).

\section{Data Analysis}

Both preprocessing and data analysis were conducted on a Silicon Graphic Indigo 2 workstation with SPM 99 (Well come Department of Cognitive N eurology, London, UK). At first, each subject's images were realigned to the first scan by calculating and applying translation and rotation parameters requisites in order to correct for head movement during acquisition. The maximal values of the translation were the following: $0.45 \mathrm{~mm}$ for the $x$ axis, $1.73 \mathrm{~mm}$ for the $y$ axis, and 1.77 $\mathrm{mm}$ for the $\mathrm{z}$ axis. All images were normalized matching each image to a MNI template (Montreal Neurological Institute) and resliced to $2 \times 2 \times 2-\mathrm{mm}$ voxel size using the bilinear interpolation method. Afterward, a smoothing procedure was applied in order to increase signal to noise ratio using an isotropic Gaussian kernel of 6-mm FWHM.

A first statistical analysis was performed for each subject according to the General linear model as implemented in SPM99; baseline drift across the imaging time series was attenuated with a high-pass filter and changes in global activity were removed by proportional scaling. Contrasts of interest (recognition vs baseline, localization vs baseline, recognition vs localization, and localization vs recognition) were estimated using a weighted square-wave function, and the respective hypotheses were tested with a t statistic generating a statistical parametrical map SPM \{t\} of corresponding $T$ values for each voxel. Regions significantly activated were considered to be those who survived a threshold of $\mathrm{T}=3.19$ ( $\mathrm{P}<0.001$ uncorrected with $\mathrm{df}=81$ ), and containing a cluster of, at least, 60 contiguous activated voxels.

The same statistical analysis and contrasts were used for the two paradigms (active response and passive listening).

Having a set of 18 subjects' acquisitions, we could consider having a reasonable statistical power to allow a population study. The statistical inference was performed according to random effects theory, so a second level t statistic was applied to our population sample for each contrast. As in a fixed effect model, the results maps were thresholded at a significance level of $\mathrm{P}<$
0.001 ( $T$ score of 3.65; different in order to the different degrees of freedom of the statistic $d f=17$ ).

The activation maps reflect responses to targets and nontargets.

Cluster coordinates were transposed in Talairach space by applying a dedicated nonlinear transformation.

\section{RESULTS}

Active Response Paradigm of Sound Recognition and Localization

Performance in tasks. All subjects included in the study attended correctly to the tasks. In each task, 30 stimuli were presented and an answer was considered as a right answer when the subject responded to a target (animal sound and different spatial positions) and when he did not responded to a nontarget. The subjects gave on average $22.6(\mathrm{SD}=4.1)$ correct replies in the localization task and 27.1 (SD = 2.1) in the recognition task. A paired t test showed a significant difference $(P=0.0006)$ in the performance between the recognition and the localization task, the latter being more difficult. A two-samples t test for the means showed no statistically significant difference in performance between men and women ( $P=0.23$ for the localization task and $\mathrm{P}=0.44$ in the recognition task).

A comparison of performance within the first and last block of acquisitions showed no significant variations in performance, which might have been due to learning or decrease in attention.

Comparison between task and rest conditions. Within the population of 18 subjects, statistical comparison of activation by the localization or the recognition task vs rest showed strong activation in tectum, medial geniculate body, medial thalamic nuclei, Heschl's gyrus, and distinct parts of the temporal, parietal, and frontal convexity on both sides (Fig. 2).

Sound recognition versus sound localization. Statistical comparison of activation by recognition vs localization (Fig. 3) or by localization vs recognition (Fig. 4) did not show significant differences in subcortical structures or in Heschl's gyrus on either side. Statistically significant differences were, however, found on both convexities, both in group and individual analyses.

Group analysis of 18 subjects showed that several regions were more activated by sound recognition than sound localization: the middle temporal gyrus on both sides, the posterior part of the inferior frontal gyrus on the left side, inferoposterior part of the precuneus bilaterally, and small regions scattered on the posterior convexity bilaterally (Fig. 5; Table 1). Other regions were more activated by sound localization than sound recognition: the inferior parietal lobule and parts of the 
premotor cortex bilaterally, prefrontal cortex, and anterior cingulate on the right side (Fig. 5; Table 2).

Statistical comparison of activation between localization and recognition or between recognition and localization in individual subjects showed very similar activation patterns as in the group analysis. Ten of the 18 subjects had a very similar distribution of selective activation patterns to recognition or to localization (for an example see Fig. 6, top row). Three subjects had sparse activation foci, in one case with indication of a lateralization, localization activating more the right, and recognition more the left hemisphere (Fig. 6, middle row). One subject had relatively sparse activation for recognition with a typical activation for localization. Four subjects showed wide spread activation foci, two selectively for recognition, one for localization, and one for recognition and localization (Fig. 6, bottom row).

Activation foci that were defined in the population analysis were also identified in individual cases, based on their anatomical position and Talairach coordinates (Tables 1 and 2). Some of these foci were found in all subjects, others only in a subpopulation.

Among the foci selectively activated by recognition, right and left temporal convexities were found in all 18 subjects, left posterior parietal cortex in 15, left frontal operculum in 14, left parahippocampal gyrus in 13, right posterior parietal cortex in 12, right parahippocampal gyrus in 11, right and left lateral occipital cortex in 8 and right insula in 7 (Table 1). Among the foci selectively activated by localization, left and right parietal Iobules were found in all 18 subjects, left dorsal premotor cortex in 17, right dorsal precuneus in 16, left dorsal precuneus in 15, right dorsal premotor cortex in 14, right dorsal prefrontal cortex in 12, right ventral prefrontal cortex in 11, right inferior frontal gyrus plus right anterior cingulate gyrus in 9 and left insula in 8 (Table 2).

\section{Passive Listening Paradigm of Sound Recognition and Localization}

The visualization of the two specialized pathways in the above paradigm might indeed reflect a genuine organizational principle of the human auditory cortex or might be due to attentional or motor aspects of the active tasks. To distinguish between these possibilities, we performed a second study in which nine subjects participated. They were not required to respond to stimuli, but just to listen to them.

Passive listening to stimuli yielded very distinct activation patterns: middle temporal gyrus and posterior prefrontal cortex on both sides were more activated by listening to meaningful than to spatialized sounds. The inferior part of the inferior parietal lobule and the posterior part of the superior temporal gyrus were more activated on both sides by listening to spatialized than to meaningful sounds (Fig. 7).

Thus, the information comprised in an auditory stimulus can preferentially drive the initial stages of one or the other auditory pathway.

\section{Sex Related Differences in Auditory Activation Pattern}

In the active response paradigm, activation patterns between men and women were compared and the analysis showed a striking-and statistically significantdifference in the number of pixels activated selectively by the recognition tasks-the women activating al most the double than the men ( $P=0.023$ in a two-samples $t$ test for the means). There was no difference between men and women in the number and in the location of activated clusters.

No statistically significant differences were obtained for the number of pixels ( $P=0.86$ in a two-samples $t$ test for the means) or the location of the clusters activated predominately by the localization task.

\section{DISCUSSION}

Investigations of activation patterns to auditory stimuli by means of fMRI BOLD technique may suffer from problems linked to difficulties in transmission of acoustic stimuli in the magnetic resonance environment. The noise of the gradient, particularly in case of EPI sequences, is in most cases as loud as or even louder than the acoustic stimulus. Several groups proposed recently that stimuli should be presented prior to acquisition (Belin et al., 1999; Hall \& al., 1999; Talavage et al., 1999; Meuli \& al., 2000); this approach eliminates interference between stimuli and gradient noise.

High temporal resolution studies of the time course of the BOLD signal, have shown that the vascular response of the BOLD signal to a short stimulus reaches its maximum about 3 to $4 \mathrm{~s}$ after stimulus onset (Belin et al., 1999), and it returns to the baseline after a latency of a few seconds, according to the stimulus duration. A longer stimulus produces a slightly higher and delayed peak of signal. Using a TR of $15 \mathrm{~s}$, a stimulus duration of $5 \mathrm{~s}$, and a sampling time of $3 \mathrm{~s}$, starting immediately after the offset of the stimulus, we were able to dissociate the BOLD effect due to the stimulus from the BOLD effect elicited by the gradient noise. Our approach was successful: epochs with presentation of auditory stimuli, as compared to rest, yielded a reliable activation in auditory structures (Fig. 1).

\section{Activation Pattern in Subcortical Structures and} the Primary Auditory Cortex

The two conditions involving auditory stimuli, as compared to rest, yielded activation in various struc- 


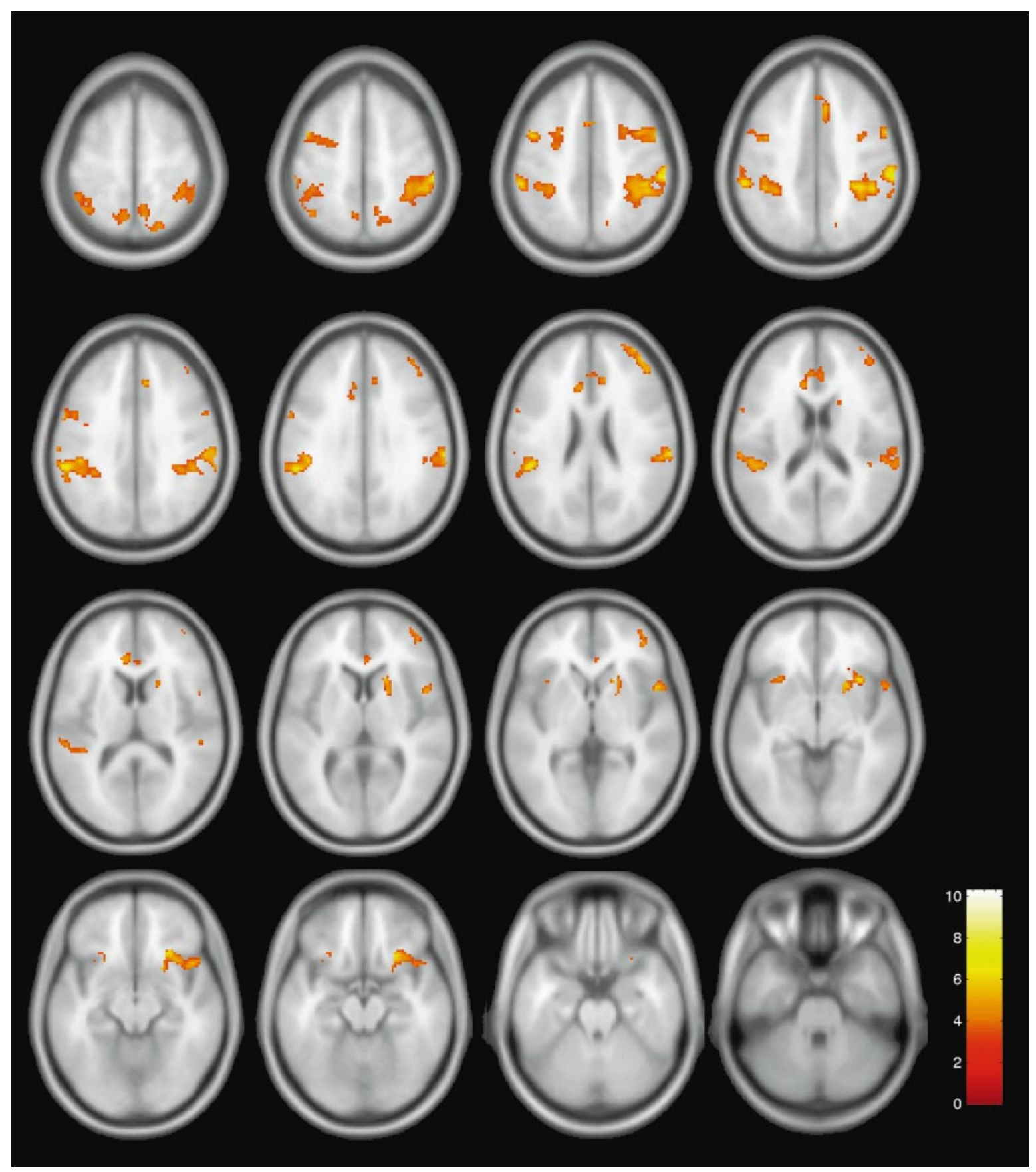

FIG. 4. Localization versus recognition on axial slices ( $z=60$ to -30 ). The left side of the figure corresponds to the left hemisphere.

tures, some of which were shown in previous studies to respond to auditory stimuli. Activation of the relay nuclei was described both for the inferior colliculus and the medial geniculate body (Lookwood et al., 1999).

The foci in midthalamus do not correspond to known auditory structures, but their activation may be related to auditory attention. Activation at the same location was found to be modulated by increase in attention to tones (Frith and F riston, 1996).

The activation of the primary auditory cortex in recognition was as described previously with PET (Enge- lien et al., 1995). Sound localization studies using the PET or fMRI methodology (Griffiths et al., 1998) described a similar activation of the primary auditory cortex.

Subcortical and primary auditory cortex activation was similar in extent and intensity for recognition and localization. Comparing conditions of specific auditory stimuli versus noise has yielded no primary auditory cortex activation for environmental sounds (Engelien et al., 1995) or auditory motion (Griffiths et al., 2000). 


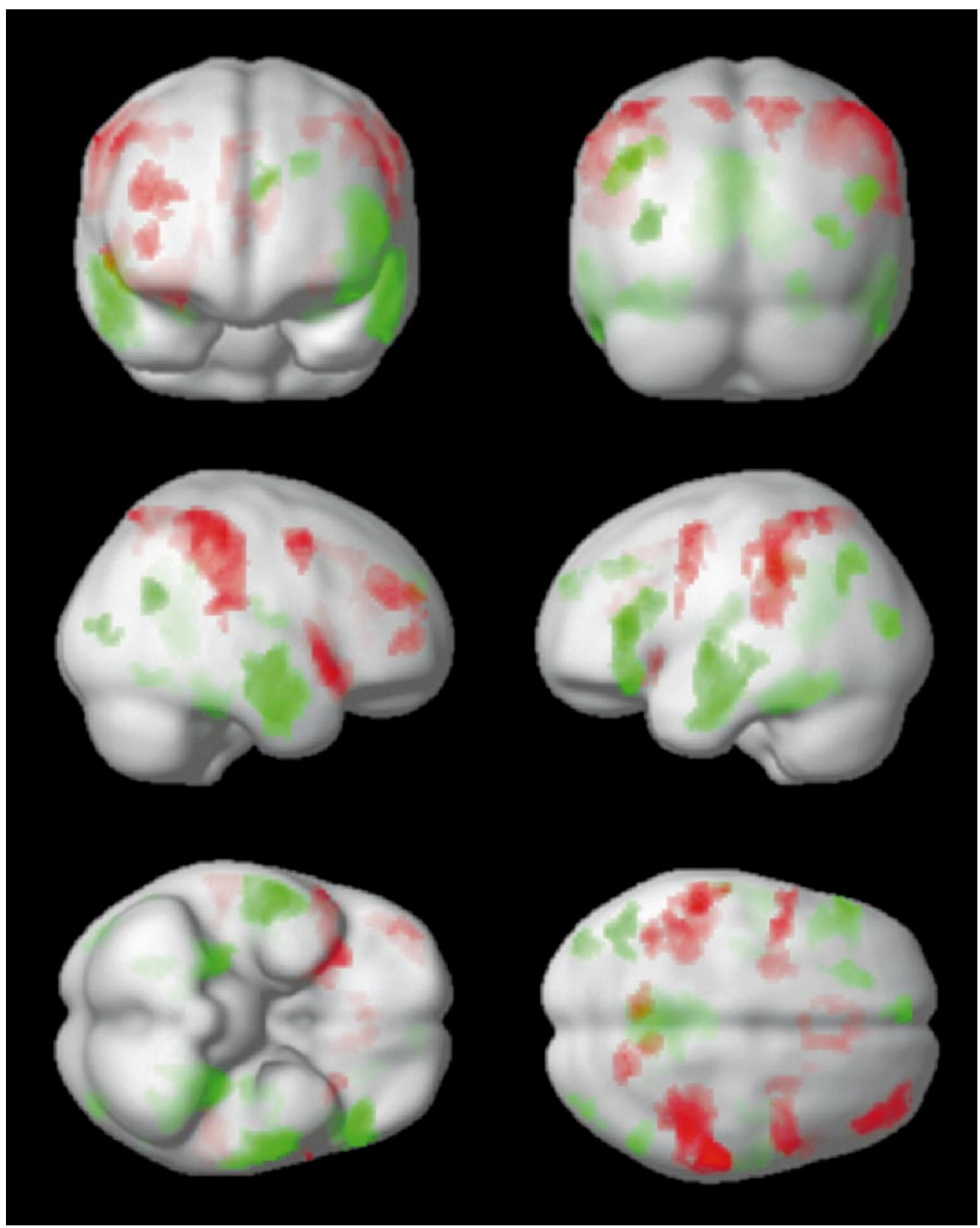

FIG. 5. Active paradigm: 3-D projections of activation on smoothed normalized brain (group results). Areas more activated in recognition than localization are shown in green, areas more activated in localization than in recognition are shown in red.

\section{Regions Selectively Activated by Sound Recognition}

Semantically relevant stimuli yielded activation mainly in the midtemporal convexity on both sides, the parahippocampal gyrus on both sides, but predominantly on the left side, the left frontal operculum and a strikingly intense activation in the ventral precuneus bilaterally. Lateral temporal regions were shown to be involved in different aspects of sound recognition by other groups. Animal studies demonstrated that lateral areas of the temporal convexities were involved in temporal pattern analysis (Dewson et al., 1970; Cowey and Weiskrantz, 1976) and recognition of intraspecies 
TABLE 1

Group Analysis: Recognition > Localization, Right and Left Hemispheres

\begin{tabular}{|c|c|c|c|c|c|c|}
\hline Anatomical location & $\begin{array}{l}\text { Cluster size } \\
\text { (in pixels) }\end{array}$ & $\mathrm{x}$ & $\mathrm{y}$ & $\mathrm{z}$ & Z score & $\begin{array}{l}\text { Cluster presence } \\
\text { in subjects }\end{array}$ \\
\hline$R$ temporal convexity $(T 2, T 3)$ & 1220 & 57 & -7 & -25 & 5.26 & $18 / 18$ \\
\hline R parahippocampal gyrus & 312 & 26 & -36 & -20 & 5.44 & $11 / 18$ \\
\hline $\mathrm{R}$ posterior parietal cortex & 168 & 50 & -57 & 23 & 4.72 & $12 / 18$ \\
\hline R lateral occipital cortex & 123 & 24 & -57 & -9 & 4.11 & $8 / 18$ \\
\hline$R$ insula & 99 & 36 & -14 & 21 & 4.16 & $7 / 18$ \\
\hline R lateral occipital cortex & 81 & 40 & -83 & 12 & 4.18 & $6 / 18$ \\
\hline L temporal convexity & 1202 & -53 & -6 & -3 & 6.01 & $18 / 18$ \\
\hline L parahippocampal gyrus & 879 & -30 & -34 & -18 & 4.81 & $13 / 18$ \\
\hline$L$ frontal operculum & 802 & -48 & 29 & -10 & 5.60 & $14 / 18$ \\
\hline L posterior parietal cortex & 276 & -44 & -66 & 38 & 4.81 & $15 / 18$ \\
\hline L lateral occipital cortex & 157 & -42 & -83 & 12 & 4.66 & $8 / 18$ \\
\hline $\mathrm{L}$ anterior middle frontal cortex & 136 & -26 & 31 & 33 & 4.03 & $11 / 18$ \\
\hline $\mathrm{L}$ anterior superior frontal cortex & 85 & -4 & 53 & 19 & 3.83 & $10 / 18$ \\
\hline Ventral precuneus (bilateral) & 2968 & -4 & -57 & 21 & 6.06 & $17 / 18$ \\
\hline
\end{tabular}

cries in non-human primates (Rauschecker et al., 1995). Human studies showed that lateral superior temporal regions were activated in the processing of speech sounds (Rauschecker et al., 1997, 1998) and environmental noises (Engelien et al., 1995; O'Leary et al., 1996). Parahippocampal gyrus has been recognized as a central component of a neural network engaged during auditory discrimination (Kikuchi et al., 1997). The activation of the left frontal operculum could be related to verbalization and semantic processing of complex sounds. Finally, the bilateral ventral precuneus activation may be due to the long-term memory retrieval for identification of the sounds (Grasby et al., 1993) and probably to the use of imagery as a retrieval strategy (Fletcher et al., 1995, 1998). The small and variable foci in lateral occipital and posterior parietal convexity suggest that parts of extrastriate visual cortex may participate in auditory recognition. The high interindividual variability of these foci precludes a simple model.

\section{Regions Sel ectively Activated by Sound Localization}

During the localization task, the largest activated clusters were found in the inferior parietal Iobule on both sides, but predominantly on the right, in the premotor cortex on both sides, in the ventral prefrontal cortex on the right and in the anterior part of the cingulate gyrus.

Neuropsychological (Clarke et al., 2000a) and functional imaging evidence (Griffiths et al., 1998, 2000; Bushara et al., 1999; Weeks et al., 1999) strongly suggests that the parietal, and in particular the right parietal region, is a key part of a larger network involved in auditory spatial functions.

This region appears involved also in attentional aspects of auditory spatial and non spatial tasks (Coull et al., 1997, 1998) and in auditory streaming (Pugh et al., 1996; Tzourio et al., 1997; Benedict et al., 1998).

In our paradigm, the attentional load was very similar in the recognition and localization tasks and the

TABLE 2

Group Analysis: Localization > Recognition, Right and Left Hemispheres

\begin{tabular}{|c|c|c|c|c|c|c|}
\hline Anatomical location & $\begin{array}{l}\text { Cluster size } \\
\text { (in pixels) }\end{array}$ & $\mathrm{x}$ & $y$ & z & Z score & $\begin{array}{l}\text { Cluster presence } \\
\text { in subjects }\end{array}$ \\
\hline R inferior parietal lobule & 1901 & 61 & -27 & 44 & 5.72 & $18 / 18$ \\
\hline $\mathrm{R}$ inferior frontal gyrus & 650 & 28 & 23 & -11 & 4.86 & $9 / 18$ \\
\hline $\mathrm{R}$ anterior cingulate gyrus & 459 & 10 & 29 & 34 & 4.30 & $9 / 18$ \\
\hline $\mathrm{R}$ dorsal premotor cortex & 295 & 53 & 4 & 42 & 4.50 & $14 / 18$ \\
\hline $\mathrm{R}$ dorsal prefrontal cortex & 245 & 42 & 46 & 18 & 4.35 & $12 / 18$ \\
\hline $\mathrm{R}$ dorsal precuneus & 209 & 8 & -55 & 60 & 4.08 & $16 / 18$ \\
\hline $\mathrm{R}$ ventral prefrontal cortex & 92 & 42 & 45 & -2 & 3.97 & $11 / 18$ \\
\hline $\mathrm{L}$ inferior parietal lobule & 1499 & -53 & -35 & 31 & 5.25 & $18 / 18$ \\
\hline L dorsal premotor cortex & 394 & -46 & 6 & 48 & 4.60 & $17 / 18$ \\
\hline L dorsal precuneus & 92 & -6 & -57 & 56 & 3.78 & $15 / 18$ \\
\hline$L$ insula & 74 & -28 & 17 & -6 & 3.66 & $8 / 18$ \\
\hline
\end{tabular}


selective activation of the parietal region may indeed reflect involvement in auditory spatial aspects.

Previous studies (Griffiths et al., 1998, 2000; Bushara et al., 1999; Weeks et al., 1999) have repeatedly found a prefrontal activation in auditory spatial tasks and proposed a parieto-frontal loop for auditory processing. These regions are near the frontal eye field and may be involved in orienting of spatial attention (Sheliga et al., 1994; Paus, 1996; Berman et al., 1999).

Right frontal and cingulate activation may be related to attention load produced by active tasks (Griffiths et al., 1994, 1998, 2000; Tzourio et al., 1997; Benedict et al., 1998). The middle portion of the ventrolateral frontal cortex and mid-dorsolateral frontal cortex are probably part of the spatial working memory processing network (Owen et al., 1996a,b, 1997, 1998).

In summary, as other studies in primates (Hackett et al., 1999; Kaas et al., 1999) and humans (Griffiths et al., 1998, 2000; Bushara et al., 1999) have pointed out, the inferior parietal region in connection with premotor and prefrontal areas represents a network involved in sound spatial perception, selective attention, and preparation of limb and saccadic eye movement.

\section{Interindividual Variations}

Although the largest and most significant clusters observed at the group level were al so present in most of the individual activation maps, variations in size and intensity were noticed among our 18 subjects. In particular, some individuals seemed to be better responders for one of the two tasks, and the hemispheric difference for each task also varied between subjects. This difference may reflect genuine interindividual differences in cortical networks or individual strategies for the treatment of similar information.

\section{Passive Listening to Semantic or Spatial Cues}

Using the passive listening task, we have demonstrated that auditory information that contains semantic but not spatial cues and that contains spatial but not semantic cues are processed by different pathways. Thus, the differential activation of the two pathways, at least at its initial stage, does not results from putative attentional or motor biases involved in the active task, but corresponds most likely to a organizational principle of human auditory cortex.

\section{Gender Differences in Activation}

To date, results about gender differences on cerebral activation are conflicting. While some studies reported no gender differences in CBF (Melamed et al., 1980; Hannay et al., 1983), others found that women had higher rates of CBF than men and that was related to age, since by the sixth decade (Gur et al., 1987) men and women had similar flow rates. PET (Rodriguez et al., 1988; Gur and Gur, 1990; J aeger et al., 1998; Ragland et al., 2000) and fMRI (Kastrup et al., 1999) studies found differences in activation during resting state (Rodriguez et al., 1988), cognitive tasks (Gur and Gur, 1990; J aeger et al., 1998; Ragland et al., 2000), or visual stimulation (Kastrup et al., 1999). Many factors were invoked to explain such a difference; blood viscosity (Shaw et al., 1984), glucose metabolism (Baxter et al., 1987; Yoshii et al., 1988), heart rate, pulse pressure, and cardiac index (Messerli et al., 1987) are higher in women than in men. Endocrine factors may also play a role (Baxter et al., 1987; Kastrup et al., 1999).

Some authors reported not only an increased CBF in women, but also a difference in activation pattern relative to men. This difference was generally expressed as a more symmetric activity in women (Rodriguez et al., 1988; J aerger et al., 1998; Ragland et al., 2000; Sadato et al., 2000). While some authors found that these differences in activation patterns were associated to a difference in performance (Gur et al., 2000; Ragland et al., 2000), other authors found that differences in activation had no effects on performance (J aerger et al., 1998; Sadato et al., 2000).

Our data revealed a statistical difference in the total number of activated pixels during the recognition task, the number of activated pixels being larger in women than in men ( $P=0.023$ in a two-samples t test for the means). Comparison for activation during the localization task showed no differences between men and women ( $P=0.86$ in a two-samples $t$ test for the means). Statistical comparisons showed no differences in performance between men and women. These results were coherent with the data of those authors who found that activation differences between men and women were not associated with differences in tasks performance (J aerger et al., 1998; Sadato et al., 2000).

\section{What and Where Networks in Human Auditory Processing}

Evidence from animal (Mishkin et al., 1983; Bachevalier et Mishkin, 1986; Kaas and Hackett, 1999; Romanski et al., 1999) and human (Haxby et al., 1991; Ungerleider and Haxby, 1994) studies demonstrated the existence of two specialized processing pathways in vision, a ventral stream involved in object vision and a dorsal stream in spatial vision.

Our study demonstrated a similar organization in human audition: in normal subjects, sound recognition, and sound localization rely on at least partially segre gated cortical networks. The sound recognition network involves the anterior part of the middle temporal gyrus and the ventral part of the precuneus on both sides and the left prefrontal cortex. Sound localization network involves the inferior parietal lobule, parts of 

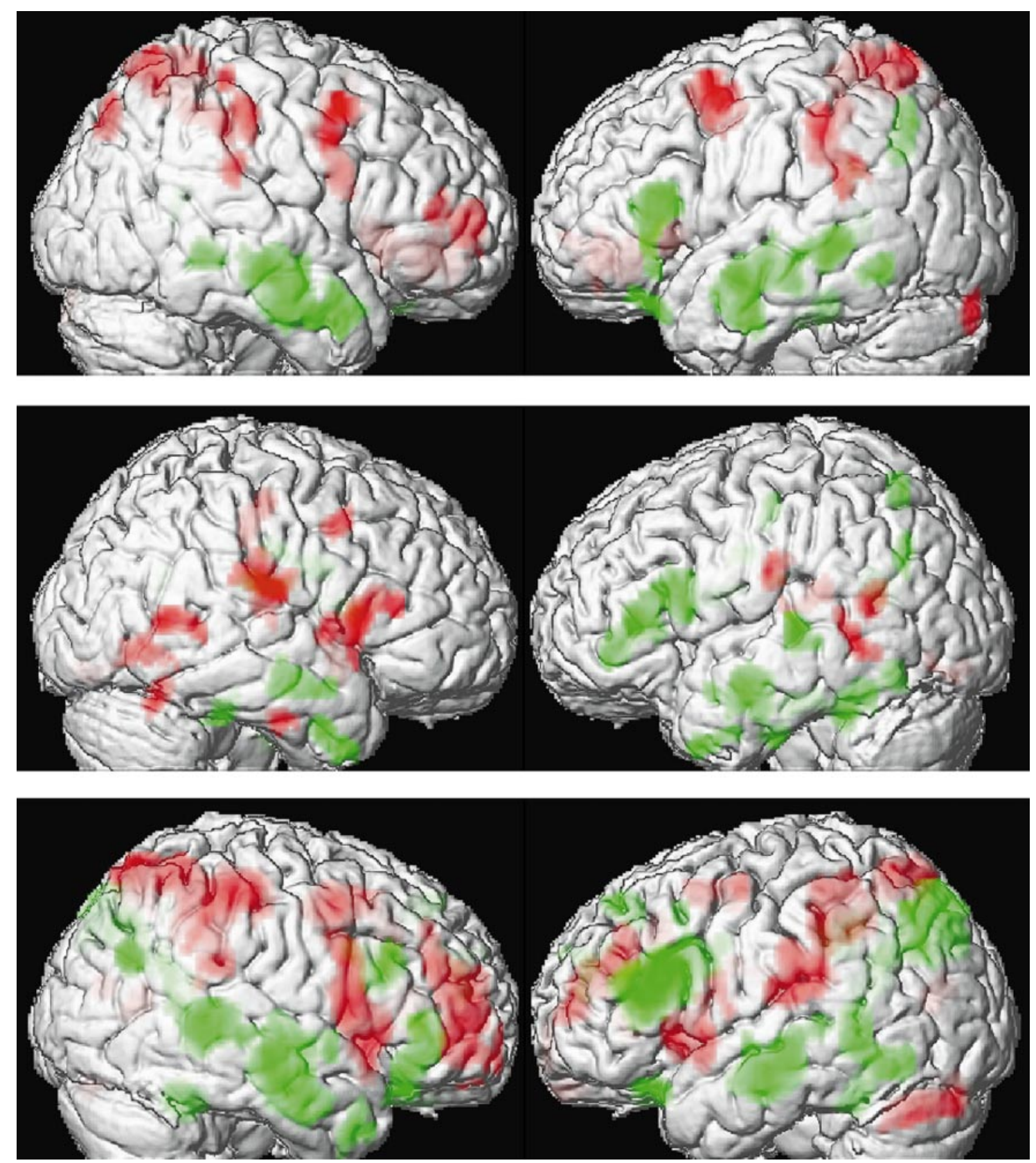

FIG. 6. 3-D projection of activation on individual segmented and normalized brains of three individual subjects showing variations in pattern activation: top row, activation pattern close to the mean; middle row, highly lateralized activation; bottom row, wide-spread activation.

the prefrontal and the premotor cortex and the dorsal part of the precuneus.

Zatorre et al. (2000) tested, and partially confirmed, the hypothesis that similar neural systems are involved in attending to spectral and to spatial features of sounds. To demonstrate this, they used the same set of stimuli, namely pure tones presented either to the left, right or both ears and asked their subjects to attend either to a particular frequency or a particular location. Both conditions, as compared to rest, acti- vated right superior parietal, dorsolateral frontal, and premotor regions, with no modulation as function of attention condition. These results do not oppose our conclusions. First, stimuli used by Zatorre et al. contained al ways spatial cues and were therefore likely to activate the spatial pathway. Second, their attend-tofrequency task did not really deal with semantic identification of sound and was thus unlikely to activate the recognition pathway. In addition, previous neuropsychological studies (e.g., Vignolo et al., 1982; Clarke et 


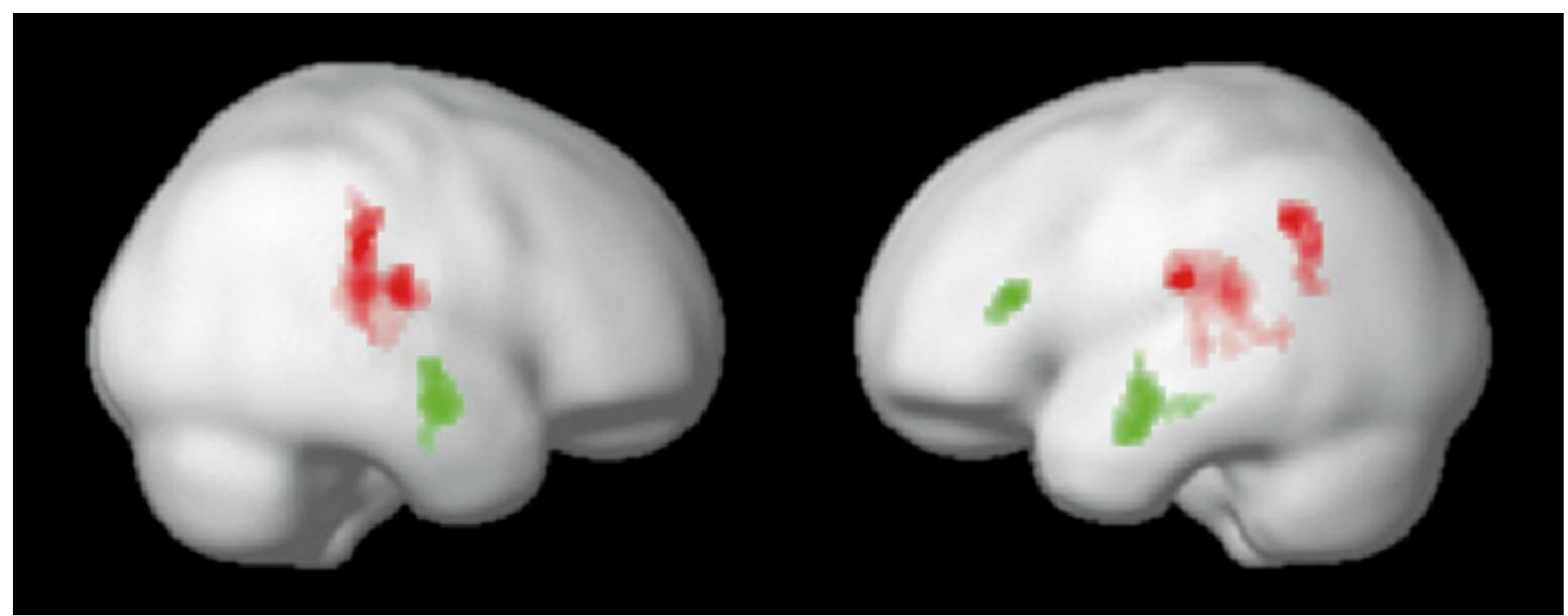

FIG. 7. Passive paradigm: $3-D$ projections of activation on smoothed normalized brain (group results). Areas more activated in recognition than localization are shown in green, areas more activated in localization than in recognition are shown in red.

al., 1996) suggest that different regions are involved in apperceptive and semantic aspects of auditory recognition.

The existence of two distinct networks has been recently confirmed by neuropsychological studies. Deficient sound recognition and normal sound localization were observed following focal lesions centered on the temporal convexity; deficient sound localization and normal sound recognition was found in association with focal parieto-frontal lesions (Clarke et al., 2000a). Moreover, psychophysical studies in normal subjects showed the existence of distinct short-term memory systems for sound content and sound localization (Clarke et al., 1998).

The question arises whether distinct early stage auditory areas, in particular putative areas on the superior temporal gyrus, can be ascribed to one or the other pathway. Our previous work demonstrated the existence of distinct auditory areas around Al (Rivier and Clarke, 1997) and of intraareal compartments within Al (Clarke and Rivier, 1998), which are putative candidates for such a specialization. The $500-\mu \mathrm{m}$-wide cytochrome oxidase stripes found in the supragranular layers of Al are too small for the spatial resolution of our fMRI study. However, our study failed to demonstrate functional specialization within cortical areas surrounding $\mathrm{Al}$, which have been shown to have a surface area of 1 to $3 \mathrm{~mm}^{2}$ in histological material. In this respect, human early stage auditory areas may differ from those in nonhuman primates; in the latter electrophysiological recordings demonstrated that the posterior part of superior temporal gyrus plays a role in auditory spatial analysis (e.g., Rauschecker and Tian, 2000).

The two separate processing pathways for auditory recognition and localization have each parts that appear to be selectively involved in the corresponding sound analysis-the middle temporal gyrus for recognition and the inferior part of the inferior parietal lobule for localization- but involve also regions known to participate in visual processing. Large parts of the parietal and premotor network visualized by the active paradigm are part of the more general attention network (Mesulam, 1990) and were shown to play a role in (visual) spatial selection (Corbetta et al., 1993). The focus in the precuneus, activated selectively by sound recognition in the active paradigm, appears to coincide with activation observed in tasks of visual recognition in an impoverished context (Dolan et al., 1997).

A dichotomy into a dorsal sound localization and a ventral sound recognition pathways is compatible with data from nonhuman primates. The discrimination of species-specific communication sounds was shown to be impaired after superior temporal cortex lesions, but not after temporoparietal lesions (H effner and Heffner, 1984, 1986; Colombo et al., 1990). Moreover, electrophysiological studies showed that, while neurons selective for auditory spatial localization were found in area LIP (Stricanne et al., 1996), neurons selective for complex sounds were found in lateral auditory areas and it has been proposed that these areas participate in the processing of communication sounds (Rauschecker et al., 1995, 1997).

The segregation between the two pathways may continue further, since the temporofrontal projections originating in areas involved in recognition and those originating in areas involved in localization have separate targets within the prefrontal cortex (Romanski et al., 1999). 


\section{CONCLUSION}

We have been able to demonstrate the activation of two different networks involved in the processing of auditory stimuli with spatial localization or pattern recognition content in the human brain.

\section{ACKNOWLEDGMENTS}

This work has been founded by the Swiss National Fund for Research FNS 3138-51173.97 (TANDEM) and by the Biomedical engineering grant of Lausanne-Geneva (1999-2000).

\section{REFERENCES}

Albert, M. L., Sparks, R., von Stockert, T., and Sax, D. 1972. A case study of auditory agnosia: Linguistic and non-linguistic processing. Cortex 8: 427-443.

Altman, J., Balanov, L., and Delgin, V. 1979. Effects of unilateral disorder of the brain hemispheric functions in man on directional hearing. Neuropsychologia 17: 295-301.

Bachevalier, J ., and Mishkin, M. 1986. Visual recognition impairement follows ventromedial but not dorsolateral prefrontal lesions in monkeys. Behav. Brain Res. 20: 249-261.

Baxter, L. R., Mazziotta, J . C., J r., Phel ps, M. E., Selin, C. E., Guze, B. H., and Fairbanks, L. 1987. Cerebral glucose metabolic rates in normal human females versus normal males. Psychiatry Res. 21: 237-245.

Belin, P., Zatorre, J ., Hoge, R., Evans, A. C., and Pike, B. 1999. Event-related fMRI of the auditory cortex. Neurol mage 10: 417429.

Benedict, R. H. B., Lockwood, A. H., Shucard, J . L., Shucard, D. W., Wack, D., and Murphy, B. W. 1998. Functional neuroimaging of attention in the auditory modality. NeuroReport 9: 121-126.

Berman, R. A., Colby, C. L., Genovese, C. R., Voyvodic, J. T., Luna, B., Thulborn, K. R., and Sweenley, K.J . A. 1999. Cortical networks subserving pursuit and saccadic eye movements in humans: An fMRI study. Hum. Brain Mapp. 8: 209-225.

Bisiach, E., Cornacchia, L., Sterzi, R., and Vallar, G. 1984. Disorders of perceived auditory lateralization after lesions of the right hemisphere. Brain 107: 37-52.

Buchtel, H. A., and Stewart, J . D. 1989. Auditory agnosia: Apperceptive or associative disorder? Brain Lang. 37: 12-25.

Bushara, K. O., Weeks, R. A., Ishii, K., Catalan, M. J ., Tian, B., Rauschecker, J . P., and Hallett, M. 1999. Modality-specific frontal and parietal areas for auditory and visual spatial localization in humans. Nat. Neurosci. 2: 759-766.

Clarke, S., Bellmann, A., de Ribaupierre, F., and Assal, G. 1996. Non-verbal auditory recognition in normal subjects and braindamaged patients: Evidence for parallel processing. Neuropsychologia 34: 587- 603.

Clarke, S., and Rivier, F. 1998. Compartments within human primary auditory cortex: Evidence fron cytochrome oxidase and acetylcholinesterase staining. Eur. J . Neurosci. 10: 741-745.

Clarke, S., Adriani, M., and Bellmann, A. 1998. Distinct short-term memory systems for sound content and sound localization. NeuroReport 9: 3433-3437.

Clarke, S., Bellmann, A., Meuli, R. A., Assal, G., and Steck, A. J . 2000a. Auditory agnosia and auditory spatial deficits following left hemispheric lesions: Evidence for distinct processing pathways. Neuropsychologia 38: 797- 807.

Clarke, S., Maeder, P., Meuli, R., Adriani, M., Bellmann, A., Fornari, E., and Thiran, J .-Ph. 2000b. What and where in human audition:
Distinct cortical processing pathways revealed by fMRI. Eur. J. Neurosci. 12(Suppl. 11): 129.

Colombo, M., D'Amato, M. R., Rodmann, H. R., and Ross, C. G. 1990. Auditory association cortex lesions impair auditory short-term memory in monkeys. Science 247: 336-338.

Corbetta, M., Miezin, F. M., Shulman, G. L., and Petersen, S. E. 1993. A PET study of visuospatial attention. J. Neurosci. 13: 1202-1226.

Coull, J. T., and Frith, C. D. 1997. Differential activation of right superior parietal cortex and intraparietal sulcus by spatial and non spatial attention. Neurol mage 8: 176-187.

Coull, J . T., and Nobre, A. C. 1998. Where and when to pay attention: The neural systems for directing attention to spatial location and to time intervals as revealed by both PET and FMRI. J . Neurosci. 18: $7426-7435$.

Cowey, A., and Weiskrantz, L. 1976. Auditory sequence discrimination in macaca mulatta: The role of the superior temporal cortex. Neuropsychologia 14: 1-10.

Dewson, J. H., Cowey, A., and Weiskrantz, L. 1970. Disruption of auditory sequence discrimination by unilateral and bilateral cortical ablations of superior temporal gyrus in the monkey. Exp. Neurol. 28: 529-548.

Dolan, R. J ., Fink, G. R., Rolls, E., Booth, M., Holmes, A., Frackowiak, R. S., and Friston, K. J . 1997. How the brain learns to see objects and faces in a impoverished context. Nature 389: 596-599.

Efron, R., Crandall, P. H., Koss, B., Divenyi, P. I . L., and Y und, E. W. 1983. Central auditory processing. III. The 'cocktail party' effect and anterior temporal lobectomy. Brain Lang. 19: 245-263.

Engelien, A., Silbersweig, D., Stern, E., Huber, W., Doring, W., Frith, C., and Frackowiak, R. S. 1995. The functional anatomy of recovery from auditory agnosia. A PET study of sound categorization in a neurological patient and normal controls. Brain 118: 1395-1409.

Faglioni, P., Spinnler, H., and Vignolo, L. A. 1969. Contrasting behavior of right and left hemisphere-damaged patients on a discriminative and a semantic task of auditory recognition. Cortex 5: 366-389.

Fletcher, P. C., Frith, C. D., Grasby, P. M., Shallice, T., Frackowiak, R. S. J ., and Dolan, R. J. 1995. Brain systems for encoding and retrieval of auditory-verbal memory. Brain 118: 401- 416.

Fletcher, P. C., Shallice, T., Frith, C. D., Frackowiak, R. S. J ., and Dolan, R. J. 1998. The functional roles of prefrontal cortex in episodic memory. II. Retrieval. Brain 121: 1249-1256.

Frith, C. D., and Friston, K. S. 1996. The role of the thalamus in “Top Down" modulation of attention to sound. Neurol mage 4: 210-215.

Fujii, T., Fukatsu, R., Watabe, S., Ohnuma, A., Teramura, K., Kimura, I., Saso, S., and Kogure, K. 1990. Auditory sound agnosia without aphasia following a right temporal Iobe lesion. Cortex 26: 263-268.

Grady, C. L., Van Meter, J . W., Maisog, J . M., Pietrini, P., Krasuski, J ., and Rauschecker, J. P. 1997. Attention-related modulation of activity in primary and secondary auditory cortex. NeuroReport 8: 2511-2516.

Grasby, P. M., Frith, C. D., Friston, K. J ., Bench, C., Frackowiak, K. S., and Dolan, R. S. 1993. Functional mapping of brain areas implicated in auditory-verbal memory function. Brain 116: 1-20.

Griffiths, T. D., Bench, C. J ., and Frackowiak, R. S. J . 1994. Human cortical areas activated by apparent sound movement. Curr. Biol. 4: 892- 895.

Griffiths, T. D., Rees, A., Witton, C., Cross, P. M., Shakir, R. A., and Green, G. G. 1997. Spatial and temporal auditory processing deficits following right hemisphere infarction. A psychophysical study. Brain 120: 785-794.

Griffiths, T. D., Rees, G., Rees, A., Green, G. G., Witton, C., Rowe, D., Buchel, C., Turner, R., and Frackowiak, R. S. 1998. Right parietal 
cortex is involved in the perception of sound movement in humans. Nat. Neurosci. 1: 74-79.

Griffiths, T. D., Green, G. G. R., Rees, A., and Rees, G. 2000. Human brain areas involved in the analysis of auditory movement. Hum. Brain Mapp. 9: 72-80.

Gur, R. C., Gur, R. E., Resnik, S. M., Skolnick, B. E., Alavi, A., and Reivich, M. 1987. The effect of anxiety on cortical cerebral blood flow and metabolism. J . Cereb. Blood Flow Metab. 7: 173-177.

Gur, R. E., and Gur, R. C. 1990. Gender differences in regional cerebral blood flow. Schiz. Bull. 16: 247-254.

Gur, R. C., Alsop, D., Glahn, D., Petty, R., Swanson, C. L., Maldjian, J . A., Turetsky, B. I., Detre, J . A., Gee, J ., and Gur, R. E. 2000. An $\mathrm{fMRI}$ study of sex differences in regional activation to a verbal and a spatial task. Brain Lang. 74: 157-170.

Hackett, T. A., Stepniewska, I., and Kaas, J. H. 1999. Prefrontal connections of the parabelt auditory cortex in macaque monkeys. Brain Res. 817: 45-58.

Haeske-Dewick, H., Canavan, A. G., and Homberg, V. 1996. Sound local ization in egocentric space following hemispheric lesions. Neuropsychologia 34: 937-942.

Hall, D. A., Haggard, M. P., Akeroyd, M. A., Palmer, A. R., Summerfield, A. Q., Elliott, M. R., Gurney, E. M., and Bowtell, R. W. 1999. ÇSparseE temporal sampling in auditory fMRI. Hum. Brain Mapp. 7: 213-223.

Hannay, J ., Leli, D., Falgout, J., Katholi, C., and Halsey, J . 1983. rCBF for middle-aged males and females during right-left discrimination. Cortex 19: 465- 474.

Haxby, J . V., Grady, C. L., Horwitz, B., Ungerleider, L. G., Mishkin, M., Carson, R. E., Herscovitch, P., Shapiro, M. B., and Rapoport, S. I. 1991. Dissociation of object and spatial visual processing pathways in human extrastriate cortex. Proc. Natl. Acad. Sci. USA 88: 1621-1625.

Heffner, H. E., and Heffner, R. S. 1984. Temporal lobe lesions and perception of species-specific vocalizations by macaques. Science 226: 75-76.

Heffner, H. E., and Heffner, R. S. 1986. Effects of unilateral and bilateral auditory cortex lesions on the discrimination of vocalizations by J apanese macaques. J . Neurophysiol. 56: 683-701.

J aeger, J .J ., Lockwood, A. H., Van Valin, R. D., J r., Kemmerer, D. L., Murphy, B. W., and Wack, D. S. 1998. Sex differences in brain regions activated by grammatical and reading tasks. NeuroReport 9: 2803-2807.

J äncke, L., Mirzazade, S., and Shah, N.J . 1999. Attention modulates activity in the primary and the secondary auditory cortex: A functional magnetic resonance imaging study in human subjects. Neurosci. Lett. 266: 125-128.

J erger, J., Loverling, L., and Wertz, M. 1972. Auditory disorder following bilateral temporal lobe insult: Report of a case. J . Speech Hear. Disord. 37: 523-535.

Kaas, J . H., and Hackett, T. A. 1999. "What" and "Where" processing in auditory cortex. Nat. Neurosci. 2: 1045-1047.

Kaas, J. H., Hackett, T. A., and Tramo, M. J . 1999. Auditory processing in primate cerebral cortex. Curr. Opin. Neurobiol. 9: 164170.

Kastrup, A., Li, T-Q., Glover, G. H., Krüger, G., and Moseley, M. E. 1999. Gender differences in cerebral blood flow and oxygenation response during focal physiologic neural activity. J . Cereb. Blood Flow Metab. 19: 1066-1071.

Kikuchi, Y., Endo, H., Yoshizawa, S., Kait, M., Nishimura, C., Tanaka, M., Kumagai, T., and Takeda, T. 1997. Human corticohippocampal activity related to auditory discrimination revealed by neuromagnetic field. NeuroReport 8: 1657-1661.

Klingon, G. H., and Bontecou, D. C. 1966. Localization in auditory space. Neurology 16: 879-886.
Lookwood, A. H., Salvi, R. J ., Coad, M. L., Arnold, S. A., Wack, D. S., Murphy, B. W., and Burkard, R. F. 1999. The functional anatomy of the normal auditory system: Responses to 0.5 and $4.0 \mathrm{kHz}$ tones at varied intensities. Cereb. Cortex 9: 65-76.

Maeder, P., Meuli, R., Adriani, M., Fornari, E., Thiran, J .-Ph., Pittet, A., and Clarke, S. 2000. Distinct pathways involved in sound recognition and localization: A human fMRI study. Neurol mage 11: S52.

Melamed, E., Lavy, S., Bentin, S., Cooper, G., and Rinot, Y. 1980. Reduction in regional cerebral blood flow during normal aging in man. Stroke 11: 31-35.

Mendez, M. F., and Geehan, G. R., J r. 1988. Cortical auditory disorders: Clinical and psychoacoustic features. J . Neurol. Neurosurg. Psychiatry 51: 1-9.

Messerli, F. H., Garavaglia, G. E., Schmieder, R. E., SundgaardRiise, K., Nunez, B. D., and Amodeo, C. 1987. Disparate cardiovascular findings in men and women with essential hypertension. Ann. Intern. Med. 107: 158-161.

Mesulam, M. M. 1990. Large-scale neurocognitive networks and distributed processing for attention, language and memory. Ann. Neurol. 28: 597- 613.

Meuli, R. A., Maeder, P., Pittet, A., Adriani, M., Fornari, E., Thiran, J.-Ph., Clarke, S. 2000. Optimisation of stimuli and acquisition technique for $\mathrm{fMRI}$ of the auditory system. Neurol mage 11: S541.

Middlebrooks, J . C., Clock, A. E., Xu, L., and Green, D. M. 1994. A panoramic code for sound location by cortical neurons. Science 264: 842- 844.

Mishkin, M., Ungerleider, L. G., and Macko K. A. 1983. Object vision and spatial vision: Two cortical pathways. Trends Neurosci. 6: 414- 417

Mountcastle, V. B. 1995. The parietal system and some higher brain functions. Cereb. Cortex 5: 377-390.

Nové-J osserand, A., Fischer, C., Nighoghossian, N., and Trouillas, P. 1998. Troubles perceptifs auditifs par lésion corticale bilatérale. Etude électrophysiologique. Rev. Neurol. (Paris) 154: 318-321.

Oldfield, R. C. 1971. The assessment and analysis of handedness: The Edinburgh I nventory. Neuropsychologia 9: 97-113.

O'Leary, D. S., Andreasen, N. C., Hurtig, R. R., Hichwa, R. D., Watkins, G. L., Ponto, L. L., Rogers, M., and Kirchner, P. T. 1996. A positron emission tomography study of binaurally and dichotically presented stimuli: Effects of level of language and directed attention. Brain Lang. 53: 20-39.

Owen, A. M., Evans, A. C., and Petrides, M. 1996a. Evidence for a two-stage model of spatial working memory processing within the lateral frontal cortex: A positron emission tomography study. Cereb. Cortex 6: 31-38.

Owen, A. M., Doyon, J., Petrides, M., and Evans, A. C. $1996 \mathrm{~b}$. Planning and spatial working memory: A positron emission tomography study in humans. Eur. J . Neurosci. 8: 353-364.

Owen, A. M. 1997. The functional organization of working memory processes within human lateral frontal cortex: The contribution of functional neuroimaging. Eur. J . Neurosci. 9: 1329-1339.

Owen, A. M., Stern, C. E., Look, R. B., Tracey, I., Rosen, B. R., and Petrides, M. 1998. Functional organization of spatial and non spatial working memory processing within the human lateral frontal cortex. Proc. Natl. Acad. Sci. USA 95: 7721-7726.

Paus, T. 1996. Location and function of the human frontal eye fields: A selective review. Neuropsychologia 34: 475- 483.

Pinek, B., and Brouchon, M. 1992. Head turning vs manual pointing to auditory target in normal subjects and in subjects with right parietal damage. Brain Cogn. 18: 1-11.

Poirier, P., Lassonde, M., Villemure, J -G., Geoffroy, G., and Lepore, F. 1994. Sound localization in hemispherectomized patients. Neuropsychologia 32: 541-553. 
Pugh, K. R., Shaywitz, B. A., Shaywitz, S. E., Fulbright, R. K., Byrd, D., Skudlarski, P., Shankweiler, D. P., Katz, L., Constable, R. T., Fletcher, J., Lacadie, C., Marchione, K., and Gore, J. C. 1996. Auditory selective attention: An fMRI investigation. Neurol mage 4: 159-173.

Ragland, J. D., Coleman, A. R., Gur, R. C., Glahn, D. C., and Gur, R. E. 2000. Sex differences in brain-behaviour relationships between verbal episodic memory and resting regional cerebral blood flow. Neuropsychologia 38: 451- 461.

Rauschecker, J . P., Tian, B., and Hauser, M. 1995. Processing of complex sounds in the macaque non primary auditory cortex. Science 268: 111-114.

Rauschecker, J . P. 1997. Processing of complex sounds in the auditory cortex of cat, monkey and man. Acta OtoL aryngol. Suppl. 532: 34-38.

Rauschecker, J . P. 1998. Parallel processing in the auditory cortex of primates. Audiol. NeuroOtol. 3: 86-103.

Rauschecker, J . P., and Tian, B. 2000. Mechanisms and streams for processing of "what" and "where" in auditory cortex. Proc. Natl. Acad. Sci. USA 97: 11800-11806.

Rivier, F., and Clarke, S. 1997. Cytochrome oxidase, acetylcholinesterase and NADPH-Diaphorase staining in human supratemporal and insular cortex: Evidence for multiple auditory areas. NeuroImage 6: 288-304.

Rodriguez, G., Warkentin, S., Risberg, J ., and Rosadini, G. 1988. Sex differences in regional cerebral blood flow. J. Cereb. Blood Flow Metab. 8: 783-789.

Romanski, L. M., Tian, B., Fritz, J., Mishkin M., Goldman-Rakic, P. S., and Rauschecker, J. P. 1999. Dual streams of auditory afferents target multiple domains in the primate prefrontal cortex. Nat. Neurosci. 2: 1131-1136.

Rosati, G., De Bastiani, P., Paolino, E., Prosser, S., Arslan, E., and Artioli, M. 1982. Clinical and audiological findings in a case of auditory agnosia. J. Neurol. 227: 21-27.

Ruff, R. M., Hersh, N. A., and Pribram, K. H. 1981. Auditory spatial deficits in the personal and extrapersonal frames of reference due to cortical lesions. Neuropsychologia 19: 435- 443.

Sadato, N., Ibañez, V., Deiber, M-P., and Hallett, M. 2000. Gender difference in premotor activity during active tactile discrimination. Neurol mage 11: 532-540.

Sanchez-Longo, L. P., and Forster, F. M. 1958. Clinical significance of impairment of sound localization. Neurology 8: 119-125.

Shaw, T. G., Mortel, K. F., Meyer, J . S., Rogers, R. L., Hardenberg, J ., and Cutaia, M. M. 1984. Cerebral blood flow changes in benign aging and cerebrovascular disease. Neurology 34: 855- 862.
Schnider, A., Benson, D. F., Alexander, D. N., and Schnider-Klaus, A. 1994. Non-verbal environmental sound recognition after unilateral hemispheric stroke. Brain 117: 281-287.

Sheliga, B. M., Riggio, L., and Rizzolati, G. 1994. Orienting of attention and eye movements. Exp. Brain Res. 98: 507-522.

Spinnler, H., and Vignolo, L. A. 1966. Impaired recognition of meaningful sounds in aphasia. Cortex 2: 337-348.

Spreen, O., Benton, A. L., and Fincham, R. W. 1965. Auditory agnosia without aphasia. Arch. Neurol. 13: 84-92.

Stricanne, B., Andersen, R. A., and Mazzoni, P. 1996. Eye-centered, head-centered and intermediate coding of remembered sound Iocations in area LIP. J . Neurophysiol. 76: 2071-2076.

Talairach, J ., and Tournoux, P. 1988. Co-Planar Stereotaxic Atlas of the Human Brain. Thieme Medical Publishers, New York.

Talavage, T. M., Edmister, W. B., Ledden, P. J ., and Weisskoff, R. M. 1999. Quantitative assessment of auditory cortex responses induced by imager acoustic noise. Hum. Brain Mapp. 7: 79-88.

Tzourio, N. E., Massioui, F., Crivello, F., J oliot, M., Renault, B., and Mazoyer, B. 1997. Functional anatomy of auditory attention studied with PET. Neurol mage 5: 63-77.

Ungerleider, L. G., and Haxby, J . V. 1994. "What" and "Where" in the human brain. Curr. Biol. 4: 157-165.

Vignolo, L. A. 1982. Auditory agnosia. Phil. Trans. R. Soc. Lond. B 298: 49-57.

Weeks, R. A., Aziz-Sultan, A., Bushara, K. O., Tian, B., Wessinger, C. M., Dang, N., Rauschecker, J . P., and Hallett, M. 1999. A PET study of human auditory spatial processing. Neurosci. Lett. 262: 155- 158.

Woldorff, M. G., Tempelmann, C., Fell, J., Tegeler, C., GaschlerMarkefski, B., Hinrichs, H., Heinze, H. J ., and Scheich, H. 1999. Lateralized auditory spatial perception and the contralaterality of cortical processing as studied with functional magnetic resonance imaging and magnetoencephalography. Hum. Brain Mapp. 7: 4966.

Yoshii, F., Barker, W. W., Chang, J . Y., Loewenstein, D., A picella, A., Smith, D., Boothe, T., Ginsberg, M. D., Pascal, S., and Duara, R. 1988. Sensitivity of cerebral glucose metabolism to age, gender, brain volume, brain atrophy and cerebrovascular risk factors. J . Cereb. Blood Flow Metab. 8: 654-661.

Zatorre, R. J ., Ptito, A., and Villemure, J -G. 1995. Preserved auditory spatial localization following cerebral hemispherectomy. Brain 118: 879-889.

Zatorre, R. J., Mondor, T. A., and Evans, A. C. 2000. Auditory attention to space and frequency activates similar cerebral systems. Neurol mage 10: 544-554. 